\begin{tabular}{l|l} 
Postprint Version & 1.0 \\
Journal website & $\underline{\text { http://dx.doi.org/doi:10.1053/eujp.2001.0330 }}$ \\
\hline Pubmed link & $\underline{\text { http://www.ncbi.nlm.nih.gov/pubmed/12036307 }}$ \\
\hline DOI & $10.1053 /$ eujp.2001.0330
\end{tabular}

\title{
Unexplained severe chronic pain in general practice
}

\author{
J. J. Kerssens, ${ }^{\text {A }}$ P. F. M. VerhaAK, ${ }^{\text {A }}$ A. I. M. BARTElds, ${ }^{\text {A }}$ M. J. Sorbi, ${ }^{\text {B }}$ AND J. M. Bensinga, ${ }^{\text {B }}$ \\ ${ }^{a}$ Netherlands Institute for Health Services Research, The Netherlands, \\ ${ }^{\mathrm{b}}$ Faculty of Social Science, University of Utrecht, The Netherlands
}

The aim of this study was to estimate the prevalence of unexplained severe chronic pain (USCP) in general practice and to report medical as well as psychological descriptions of patients suffering from this condition.

A total of 45 GPs in 35 different practices included patients throughout the year 1996. Patients were included according to the following criteria: between 18 and 75 years of age; pain which had lasted at least 6 months; pain is the most prominent aspect in the clinical presentation; pain is serious enough to justify clinical attention; pain has led to obvious discomfort and disability in daily life for at least for 1 month. Medical aspects were measured with the IASP taxonomy while psychological aspects were derived from the MPI.

The overall prevalence of USCP was 7.91 per 1000 enlisted patients. Estimates ranged between 1.87 in the youngest age group and 13.50 in the 55-59 age category. The lower back and lower limbs were most frequently affected and 31\% of the patients had pain in more than three major body sites. Pain was most frequently associated by the musculoskeletal system and most often (nearly) continuous. Mean severity of current pain was 3.7 on a scale from 0 (indicating no pain) to 6 (indicating a lot of pain). Mean rating of 'average pain in the last week' was 4.1. Regarding the psychosocial and behavioural aspects of pain, $27 \%$ of the patients could be described as perceiving severe pain while gaining social support for it. Fourteen per cent felt in the category 'pain combined with affective and relational distress' and $10 \%$ was classified as 'coping well with pain intensities lower than those of the other groups'. The other half of the patients were on average or not classifiable on these aspects.

Unexplained severe chronic pain lasting more than 6 months had on overall prevalence of 7.91 per 1000 enlisted patients, ranging from 1.87 in the youngest to 13.50 in the oldest patients in these 35 general practices in The Netherlands. Our prevalence estimate of USCP is low compared to other studies on chronic pain. Probably for three reasons: Firstly, our study was confined to unexplained pain and not all chronic pain. Secondly, our inclusion criteria focused the attention of very severe chronic pain patients, and thirdly, we have defined 'chronic' as more than 6 months, while others have been using shorter time spans. 


\section{INTRODUCTION}

Pain is a common presenting symptom in general practice and its relief is seen as an important task for health care professionals. In addition to its acute form, pain can be chronic and it is critical that both forms are considered as separate entities (Clifford, 1993). Acute pain is a collection of experiences and responses produced by tissue damage or acute disease. It is a precise and well-localized symptom, which generally resolves during the early stages of tissue healing. Chronic pain, on the other hand, is pain that persists beyond the normal time of healing (Bonica, 1953). Healing time may vary with the tissue involved, with the injured body site and the extent of tissue destruction.

\section{Unexplained chronic pain}

In chronic pain a direct link with a nociceptive substrate is not always present. When there is no such link, we refer to unexplained chronic pain. The complex nature of unexplained chronic pain implicates that its prevalence cannot be measured by means of well defined diagnostic procedures. Unexplained chronic pain is a matter of exclusion, made reluctantly after a battery of appropriate investigations have yielded no results. Therefore, it is always relative to the state of art in medicine. For example, it now has been suggested that phantom pain can be related to a decreased blood flow in the residual limb (Sherman et al., 1992), where formerly no cause was considered for the spontaneous and evoked hyper excitability of neurons (Merskey, 1986). Unexplained chronic pain is a complex phenomenon, caused by many different factors and modulated by a variety of influences (Seers, 1992). It requires a multidimensional approach incorporating a number of dimensions such as the localization of pain, pain intensity, temporal characteristics, affective appraisal, coping, and grading of pain (see VonKorff et al., 1990; VonKorff, 1992; Turk and Rudy, 1992; Raspe and Kohlman, 1994). Such a multidimensional approach should incorporate medical assessments, as elaborated by the International Association for the Study of Pain, with the following five axes: (1) body region; (2) body system; (3) temporal characteristics; (4) pain intensity and time of onset; and (5) the presumed aetiology. In addition to this psychosocial and behavioural aspects should be assessed. This approach is called the Multiaxial Assessment of Pain (MAP; Kerns et al., 1985; Lousberg et al., 1999).

On the basis of current knowledge and existing figures (derived from unidimensional, medical approaches), it is not possible to give a reliable estimate of the prevalence of chronic pain (Verhaak et al., 1998). Nevertheless, high costs have been attributed to the phenomenon of chronic pain. It has been reported that 10,000 patients who are unable to work because of pain are registered each year in the Netherlands (Lousberg, 1994). Aronoff et al. (1983) estimated that chronic pain costs America 40 billion dollars a year. Because of the lack of reliable figures, the Netherlands Organization for Scientific Research commissioned the Netherlands Institute for Health Services Research (Nivel) to estimate the prevalence of unexplained severe chronic pain among adults in general practice.

This has been done, using a multi-axial approach and general practice populations as the population at risk. This has been done, because GPs have a central position in the Dutch health care system. They are the first health professionals to contact in case of health related problems (Maarse, 1997). Most of the other health services, including medical specialists and physiotherapists are accessible only after a referral of a GP (Kerssens and Groenewegen, 1990). Besides that, patients are registered with a GP in a fixed list. More than $75 \%$ of the population see their GP at least once a year. For chronically ill people this percentage is even 94\% (Rijken et al., 1999). It was therefore assumed that GPs were a good intermediary for the detection of cases of unexplained severe chronic pain (USCP).

We have formulated the following research questions:

-What is the overall and the age specific prevalence of USCP?

-What kind of body regions, body system are involved?

-What are the temporal characteristics of USCP?

-What kind of psychological, social and behavioural implications result from USCP?

\section{METHODS}

\section{GPs}

Since 1970, a number of Dutch GPs are participating in the Dutch Sentinel Practice Network (Claas et al., 1995; Moons et al., 1996; Bartelds, 1997). These sentinel stations have been requested to report each patient known to have chronic pain. Their practice population, counted every 2 years, is recorded 
in age-categories for both males and females. In our project, 45 GPs in 35 different practices agreed to take part. These sentinel stations covers $0.67 \%$ of the Dutch population. In Table 1, a comparison is given for the age and sex distribution of the practice population and the Dutch population as a whole.

\section{[ TABLE 1 ]}

With the exception of the youngest and oldest groups, age categories are in 5-year intervals. The two right most columns ('total') reveal that the sentinel stations have slightly more people in the 18-24, 25$29,30-34$ age categories. The difference in the age category $25-29$ is largest (compare $11.4 \%$ with $12.6 \%)$. This pattern is the same for both males and females. The percentage of males and females in the practice population is exactly the same as in the Dutch population (50\%-data not in table). Although the differences between the age-distribution of the sentinel stations, compared with the Dutch population, are modest, prevalence estimates will be corrected for these age differences.

\section{Patients}

Patients were asked by their GPs in the period 1/1/1996 through 31/12/96 to cooperate with our project. The following criteria were used by the GPs to include patients:

1. Patients between 18 and 75 years of age;

2. Patients with pain which had lasted at least 6 months;

3. Pain is the most prominent aspect in the clinical presentation;

4. Pain is serious enough to justify clinical attention;

5. Pain has led to obvious discomfort and disability in daily life for at least for 1 month.

Exclusion criteria were: patients with pain caused by diagnosed malignancies, rheumatic or neurological disorders, such as cancer, rheumatoid arthritis and gout.

The second criterion served as a time frame to investigate the incidence of USCP. Six months is a conventional point of division between chronic and sub-acute pain. Only after having pain for at least 6 months were patients included in our database. During 1996, it became clear that a majority of the GPs were unable to apply the project's inclusion criteria on a day-to-day bases. Consequently, we visited all the practices at the beginning of 1997 to look for further USCP patients. Where the practicecomputer system was compatible, we searched for appropriate ICPC codes (International Classification of Primary Care) or ATC codes (Anatomical-Therapeutical-Chemical). We looked for pain syndromes or pain medication. Where the practice-computer system was not useful in this respect, we went through a list of pain syndromes with the GP and the GP-assistant. This approach enabled us to estimate the prevalence, but not the incidence of USCP.

\section{Measurement instruments}

To obtain medical aspects of USCP, a registration form was developed on basis of the five IASP axes. This form was completed by the GP at the time of inclusion. Altogether a number of 586 patients fulfilled the inclusion criteria and had pain for at least six months. The five IASP axes mentioned earlier were all covered on the registration form.

On the moment of inclusion GPs also handed out consent forms and the Multidimensional Pain Inventor (MPI; Dutch Version), which the consenting patients completed at home and then returned to the Nivel. The group of patients that were selected during the practice visits got the consent form and the MPI by mail. Altogether a number of 344 patients (59\%) returned their consent forms and the self completed MPI (DV).

The Multidimensional Pain Inventory (MPI-DV) covers psychological, social and behavioural aspects of the chronic pain disorder; The MPI is a self-report questionnaire which measures patient's appraisal of pain and the impact of pain on different domain of daily lives. The following scales are part of the MPI: Pain Severity; Interference; Life Control; Affective Distress; Support; Punishing Response; Solicitous Response; Distracting Response; Household Chores; Outdoor work; Social Activities; General Activities.

The self-assessment by the MPI leads to four distinct patient profiles; Dysfunctional patients, who perceive the severity of their pain to be high, report pain to interfere with their daily lives and have a low activity level. However, they experience more than average social support. Interpersonally 
distressed patients who have moderate pain and affective distress and have a common perception that significant others are not very understanding.

Adaptive Coping patients who experience much social support and relatively low levels of pain, affective distress and high levels of activity and perceived control. And finally the Average type of patient who has characteristics of all three types. Patients with contradictory values on different scales (a.o. because of missing values) are categorized as 'anomalous'.

\section{Statistics}

Most statistics are descriptive, like means and percentages. Association between variables is computed with a non-parametric correlation coefficient (Spearman's rho) with interval variables and Chi-square analyses with nominal variables.

\section{RESULTS}

\section{Consent and non-consent}

Already mentioned was the fact that 344 patients (59\%) returned their consent forms. There were some differences between those who consented and those who did not. Consenters were on average 3.5 years younger $(p=0.02)$ and had relatively more often pain on three major body sites or more $(p=0.004)$. With regard to gender and time of onset of pain there were no statistically significant differences.

\section{Prevalence}

Based on 586 included patients with unexplained severe chronic pain and because of the correction for age, a number of 604 cases were calculated out of a total of 76,367 enlisted patients between 18 and 75. So the prevalence estimate of USCP in general practice was 7.91 per 1000 patients.

The majority of the patients was female (71\%). The age specific prevalence estimates are given in Table 2. Both sexes had the same distribution according to age.

\section{[ TABLE 2 ]}

Estimates ranged between 1.87 per 1000 in the youngest group and 16.95 in the age category 50-54 years. Next highest was 13.50 per 1000 in the 55-59 year category. The estimates were relatively low below the age of 34 .

\section{Medical aspects of pain}

Table 3 shows the patients with USCP according to the major site of the body with pain.

\section{[ TABLE 3 ]}

The number of major sites exceeded the number of patients because more than one site can be recorded. In fact 106 patients (31\%) had pain in more than three major sites. The rest of the patients had pain in less than three sites, 1.7 sites on average. The lower back and the lower limbs were most frequently recorded, often in combination with each other. The upper shoulder/ upper arms and the cervical region were also frequently recorded.

The various body systems associated with pain are shown in Table 4.

\section{[ TABLE 4 ]}

The pain was most often associated by the musculoskeletal system and connective tissue (in $48 \%$ of the patients). From the single systems, the nervous system was recorded in $9 \%$ of the patients. Another frequently recorded category was `more than one system' (34\%), most often a combination of musculoskeletal - and nervous system. The other body systems of Table 4 were rarely recorded. The temporal characteristics of the pain (in terms of the IASP system) are depicted in Table 5. 


\section{[ TABLE 5 ]}

Most often the pain was continuous or nearly continuous with fluctuating severity (38\%) or irregularly recurring.

\section{Subjective experience}

On a scale from 0 (indicating no pain) to 6 (indicating a lot of pain) the mean rating of current pain was 3.7 (SD 1.7), while the mean rating of 'average pain in the last week' was 4.1 (SD 1.5). There is a significant correlation between the pain ratings (Spearman's rho $0.67(p<0.001)$ ). The pain severity index-the mean of the two ratings is 3.9 (SD 1.5).

Pain severity is one aspect of the Multidimensional Pain Inventory. The other aspects (or dimensions) are in Table 6.

\section{[ TABLE 6 ]}

The aspect with the highest mean scale score was `support', that is the appraisal of the amount of support received from spouse or a significant other. The next highest mean was associated with perceived 'life control', that is the perceived ability to solve problems and feelings of personal mastery and competence. The two lowest mean scales scores were 'punishing responses', which is the patient's report of the negative (for instance irritability) responses by spouses of significant others (score 1.16) and 'outdoor work'.

Each patient's scores resulted in a profile, as explained in the Method section. The MPI program utilizes these scores to assign each patient one of three empirically-derived prototypic profiles. These prototypes are shown in Table 7.

\section{[ TABLE 7 ]}

The dysfunctional type was seen most often (27\%). The interpersonally distressed and the adaptive copers were seen less frequently. Notice that about half of the profiles are `average' or 'anomalous'.

\section{DISCUSSION}

The prevalence estimate of unexplained severe chronic pain (USCP) in general practice is 7.91 per 1000 enlisted patients and for reasons stated above, we believe that this figure comes close to the prevalence of USCP (with pain that is serious enough to justify clinical attention and obvious discomfort and disability in daily life) in the open population.

Seventy percent of the patients with USCP is female and the prevalence estimates are highest between 50-54 years of age. Lower back, neck, and shoulder are the body areas most frequently affected. In USCP most patients are troubled by pain in several parts of their bodies, like patients with fibrositis. Apart from those, lower back pain is encountered about as equal as pain in the shoulder/arms, or pain in the legs. Pain is most frequently associated by the musculoskeletal system and most often (nearly) continuous. Mean severity of current pain was 3.7 on a scale from 0 (indicating no pain) to 6 (indicating a lot of pain). Mean rating of `average pain in the last week' is 4.1. About one third of the patients could be described as patients with serious pain who gained considerable social support as a result of their suffering. In about one sixth, pain seemed to be related to affective and interrelational problems.

Epidemiological studies in the open population, as well as in general practice have shown that chronic pain represents a major public health problem (Crook et al., 1984; Andersen, 1987; Brattberg et al., 1989; Magni et al., 1990; Mäkélä and Heliövaraa, 1991; Potter, 1992; Croft et al., 1993; Anderson, 1994; Elliot et al., 1999). One problem of these studies is that their estimates of the prevalence of chronic pain range from less than 1\% (Potter, 1992) to 82\% (James, 1991) which may be partly explained by differences in the definition of pain (Crombie, 1994; Purves et al., 1998). Furthermore, Verhaak et al. (1998) demonstrated that different kinds of methods for the study of chronic pain (telephone surveys, postal questionnaires, direct interviews) all yielded wide ranges of estimates. 
Our prevalence estimate is low compared with most of these studies. Probably for three reasons. Firstly, our project was confined to unexplained pain, and not all chronic pain, which will obviously make a difference. Arecently published study from Finland showed that about $8 \%$ of patients had experienced pain for over 6 months while 1.1\% of patients had unexplained pain lasting over 6 months (Mäntyselkä et al., 2001). Secondly, our inclusion criteria 3, 4 and 5, based on the DSM-IV, (pain is the most prominent aspect in the clinical presentation; pain is serious enough to justify clinical attention; and pain has led to obvious discomfort and disabilities in daily life) has focused the attention on very severe chronic pain patients, in contrast to other studies where patients are 'often troubled by pain' (Crook et al., 1984), or using the term `chronic' without any specification (Mäkélä and Heliövaara, 1991; Andersen, 1994; Croft et al., 1993). So we did not only look for unexplained pain, but also for severe chronic pain. A third reason in comparison with other studies is that we have operationally defined 'chronic' as more than 6 months. Theoretically, the longer the time span, the fewer patients will be found. A well designed study of VonKorff et al. (1988) showed that, while 37\% reported recurrent pain, only $8 \%$ had severe and persistent pain and less than $3 \%$ had such pain lasting more than 6 days.

There is in the literature some consensus about the characteristics of the patients who suffer from chronic pain: they are relatively often middle-aged women. This agrees with our findings. Lower back, neck, and shoulder are the body areas most frequently affected, in our study as well as in previous studies.

Chronic pain is often associated with depression or other kinds of psychological distress. Blyth et al. (2001) found some psychological distress in chronic pain patients (compared to persons without pain) and a lot of psychological distress in males and females reporting interfering chronic pain. Our patients also reported that the pain interfered with their daily activities and they also reported a lot of affective distress. The MPI tries to cover psychological, social and behavioural aspects of the chronic pain disorder. The MPI has been widely used in pain-clinics. Compared to our patients, in general practice, a heterogeneous chronic pain clinic sample (Rudy, 1989) had much more affective distress, and more interference with daily life activities. Patients in pain clinics also rated their pain as more severe and elicited more punishing response from their partners. Patients in general practice are able to perform more activities than patients in pain clinics. Figures of a homogeneous sample of pain clinic patients show the same results (Lousberg et al., 1997). All these finding are consistent with the circumstance that patients in pain-clinics experience more illness-burden than patients in general practice.

One could question if the study was not limited by using the general practice as population at risk. Therefore, this study is not a community study and hence does not provide estimates of pain prevalence in the population. However, as we pointed out, in the Netherlands GPs have a central role in the health care system. Most other health professionals cannot be consulted without a GP's referral. So if chronic pain patients in the population choose to visit physiotherapists or complementary practitioners they still need to go to the GP for a referral. When it became clear that a majority of the GPs was unable to apply the project's inclusion criteria on a day-to-day bases, we visited all the practices at the beginning of 1997 to look for further USCP patients. So even if a patient did not visit their GP in 1996 chances are high that he or she was included in the record review in 1997.

A major methodological problem remains the lack of true diagnostic criteria for USCP. The complex nature of chronic pain means that its prevalence cannot be measured by means of assessing welldefined physical conditions as is the case with diabetes or malaria. Accordingly chronic unexplained pain is partly a matter of interpretation. The variation between participating doctors in their reported prevalences is illustrative for this problem. Some sentinel GPs who meticulously recorded patients during 1 year had prevalence estimates up to 24.68 per 1000 patients. Other GPs did not include a single patient during that year. A multi-axial approach is helpful for a better understanding and interpretation of the patients, but is does not solve the problem of case-finding. We suppose that it is likely that, given some under-registration, patients with less severe pain will be less likely to be registered. One would therefore predict that GPs with low registration rates would have on average more patients with severe pain. However, there is no significant correlation between the GP registration rates and the average pain intensity of their patients.

In the course of the study we encountered cultural problems as well. Doctors with a lot of foreign patients told us that patients from north African countries often give chronic pain as a reason for 
encounter even if their medical condition is the same as that of patients from other countries who will give other reasons for encounter. The same phenomenon is reported by Gureje et al. (1998) who encountered large variations in frequency across pain centres in different countries.

This study reveals a number of findings that are of practical value in general practice.

At first, there is the large variation between GPs in their perception of chronic inexplicable pain. This might be an indication for the diagnostic difficulties a GP faces when he or she is confronted with enduring unexplained pain complaints. It might be important for the GP to explore patients' views of the pain and particularly his way of coping with it. The relatively large number of people who combine severe pain reports with lots of social support without altering the pain behaviour in the long run is a sign of undesirable behaviour that keeps being reinforced. In such cases cooperation between GPs and psychologists might be a possibility to change such behaviour.

Another finding, that runs in line with the former remarks is the regularly found combination of pain with distress. Here again, the cooperation of medical doctors and psychological services might be of great help.

An improved understanding of chronic pain has led to significant advances in the management of this major and complex health problem (Smith et al., 1999). Managing chronic pain in general practice should be based on the assertion that chronic pain is never a symptom that exists in isolation. Even with unknown pathophysiology, it tends to create a cluster of related problems such as chronic fatigue, sleep disturbance, excessive rest and withdrawal from activity, compromised immune function and mood disorder. The physician should made every effort to prevent pain and to relieve pain promptly and effectively when it does occur. How patients think about their pain and whether the physician seems to care about the pain and its relief are also crucial factors (Chapman and Gavrin, 1999).

What is needed is a differentiated approach of pain patients, dependent on their differences in medical, psychological and behavioural respects, as indicated by the IASP classification and MPI score. Factors that need to be considered for the effective management of chronic pain include the somatic source for the pain, the patient's emotional status and personality, family factors, previous pain experiences, cultural factors affecting pain expression, education, and encounters with professional caregivers (Librach, 1993). However, our study revealed also that, compared with studies carried out in specialized pain clinics, patients in general practice have less serious symptoms than patients in clinical settings. This is only natural and common in all sectors of health care. As a result, approaches developed in multidisciplinary pain centres are not always applicable in the general setting nor is it possible to refer all patients with USCP in general practice to a pain clinic. Therefore, two developments in general practice are critical in our view:

Firstly: GPs should make an effort to develop guidelines for differentiated diagnosis and treatment of chronic pain in general practice. These guidelines should be inspired by the work done in specialist clinics but adapted to the restrictions of general practice and the general practitioners

Secondly: GPs and specialists as well should strengthen their mutual bonds, wherever they exist and should develop them in case there is no relationship yet, lest the knowledge of pain specialists can spread to general practice and general practice can fall back on the specialist.

\section{ACKNOWLEDGEMENTS}

This study was financed by the Netherlands Organization of Scientific Research (NWO- 940-31-003). We would also like to thank the participating GPs of the Dutch Sentinel Network. 
Kerssens, J.J., Verhaak, P.F.M., Bartelds, A.I.M., Sorbi, M.J., Bensing, J.M.

Unexplained severe chronic pain in general practice.

European Journal of Pain: 6, 2002, p. 203-212

TABLES

TABLE 1. Population of the Netherlands between 18 and 75 years of age by sex per 5 years age group compared to the practice population of the sentinel stations.

\begin{tabular}{|c|c|c|c|c|c|c|}
\hline & \multicolumn{2}{|c|}{ Male } & \multicolumn{2}{|c|}{ Female } & \multicolumn{2}{|c|}{ Total } \\
\hline & Neth. & Sent. & Neth. & Sent. & Neth. & Sent. \\
\hline $18-24$ & $708694(12.5)$ & $4842(12.7)$ & $688100(12.1)$ & 5147 (13.5) & $1396794(12.3)$ & 9989 (13.1) \\
\hline $25-29$ & $657393(11.6)$ & 4906 (12.9) & $631787(11.2)$ & 4739 (12.4) & $1289180(11.4)$ & 9645 (12.6) \\
\hline $30-34$ & 675944 (11.9) & $4772(12.5)$ & $643984(11.4)$ & 4424 (11.6) & $1319928(11.6)$ & 9196 (12.0) \\
\hline $35-39$ & $638530(11.2)$ & $4312(11.3)$ & $618249(10.9)$ & $4020(10.5)$ & $1256779(11.1)$ & $8332(10.9)$ \\
\hline $40-44$ & $591425(10.4)$ & $3838(10.1)$ & $574814(10.1)$ & 3788 (9.9) & $1166239(10.3)$ & $7626(10.0)$ \\
\hline $45-49$ & $593093(10.4)$ & $3856(10.1)$ & $570992(10.1)$ & $3870(10.1)$ & $1164085(10.3)$ & $7726(10.1)$ \\
\hline $50-54$ & 505665 (8.9) & 3017 (7.9) & 484946 (8.6) & 2905 (7.6) & $990611(8.7)$ & $5922(7.8)$ \\
\hline $55-59$ & $396568(7.0)$ & 2579 (6.8) & $390210(6.9)$ & $2464(6.4)$ & 786778 (6.9) & $5043(6.6)$ \\
\hline $60-64$ & $340724(6.0)$ & $2277(6.0)$ & $354272(6.3)$ & $2333(6.1)$ & $694996(6.1)$ & $4610(6.0)$ \\
\hline $65-69$ & $294909(5.2)$ & 1859 (4.9) & $337506(6.0)$ & $2190(5.7)$ & $632415(5.6)$ & 4049 (5.3) \\
\hline $70-75$ & 278344 (4.9) & $1846(4.8)$ & $372180(6.6)$ & $2383(6.2)$ & $650524(5.7)$ & $4229(5.5)$ \\
\hline Total & 5681289 & 38104 & 5667040 & 38263 & 11348329 & 76367 \\
\hline
\end{tabular}

TABLE 2. Age specific prevalence estimates of USCP in general practice. Estimates are based on 344 patients.

\begin{tabular}{cccc}
\hline & $\begin{array}{c}\text { Estimate per } \\
\text { 1000 patients }\end{array}$ & $\begin{array}{c}\text { Estimated } \\
\text { number }\end{array}$ & $\begin{array}{c}\text { Practice } \\
\text { population }\end{array}$ \\
\hline $18-24$ & 1.87 & 19 & 9989 \\
$25-29$ & 1.59 & 15 & 9645 \\
$30-34$ & 3.52 & 32 & 9196 \\
$35-39$ & 8.98 & 75 & 8332 \\
$40-44$ & 10.71 & 82 & 7626 \\
$45-49$ & 10.35 & 80 & 7726 \\
$50-54$ & 16.95 & 100 & 5922 \\
$55-59$ & 13.50 & 68 & 5043 \\
$60-64$ & 10.33 & 48 & 4610 \\
$65-69$ & 8.82 & 36 & 4049 \\
$70-75$ & 11.26 & 48 & 4229 \\
Total & 7.91 & 604 & 76367 \\
\hline
\end{tabular}

TABLE 3. Major sites of the body with pain $(n=344)$.

\begin{tabular}{lrc}
\hline & Number & $\begin{array}{c}\text { percentage } \\
(\%)\end{array}$ \\
\hline Head, face and mouth & 62 & 12.1 \\
Cervical region & 56 & 10.8 \\
Upper shoulder and & 76 & 14.7 \\
$\quad$ upper limbs & 35 & 6.8 \\
Thoracic & 30 & 5.9 \\
Abdominal region & 72 & 13.9 \\
Lower Back, lumbar spine, & & \\
sacrum and coccyx & 66 & 12.8 \\
Lower limbs & 5 & 0.9 \\
Pelvic region & 8 & 1.5 \\
Anal, perineal, genital region & 106 & 20.4 \\
More than three major sites & 516 & 100.0 \\
Total & & \\
\hline
\end{tabular}

TABLE 4. Various body systems associated with pain $(n=344)$.

\begin{tabular}{|c|c|c|}
\hline & Number & $\begin{array}{l}\text { Percentage } \\
\quad(\%)\end{array}$ \\
\hline Nervous system & 32 & 9.3 \\
\hline $\begin{array}{l}\text { Respiratory and cardiovascular } \\
\text { system }\end{array}$ & 2 & 0.6 \\
\hline $\begin{array}{l}\text { Musculoskeletal system and } \\
\text { connective tissue }\end{array}$ & 164 & 47.7 \\
\hline $\begin{array}{l}\text { Cutaneous, subcutaneous and } \\
\text { associated glands }\end{array}$ & 1 & 0.3 \\
\hline Gastrointestinal system & 6 & 1.7 \\
\hline Genito-urinary system & 3 & 0.9 \\
\hline Other organs or viscera & 1 & 0.3 \\
\hline More than one system region & 117 & 34.0 \\
\hline Total & 344 & 100.0 \\
\hline \multicolumn{3}{|c|}{ TABLE 5. Temporal characteristics of pain $(n=344)$. } \\
\hline & Number & $\begin{array}{l}\text { Percentage } \\
(\%)\end{array}$ \\
\hline $\begin{array}{l}\text { Continuous or nearly } \\
\text { continuous, nonfluctating }\end{array}$ & 57 & 16.7 \\
\hline $\begin{array}{l}\text { Continuous or nearly } \\
\text { continuous, fluctating } \\
\text { severity }\end{array}$ & 132 & 38.3 \\
\hline Recurring, irregularly & 70 & 20.4 \\
\hline Recurring, regularly & 45 & 13.1 \\
\hline Paroxysmal & 12 & 3.6 \\
\hline $\begin{array}{l}\text { Sustained with superimposed } \\
\text { paroxysms }\end{array}$ & 12 & 3.6 \\
\hline Other combinations & 0 & 0 \\
\hline Total & 344 & 100.0 \\
\hline
\end{tabular}


Kerssens, J.J., Verhaak, P.F.M., Bartelds, A.I.M., Sorbi, M.J., Bensing, J.M.

Unexplained severe chronic pain in general practice.

European Journal of Pain: 6, 2002, p. 203-212

TABLE 6. Mean and standard deviations of MPI-DLV scores of USCP patients.

\begin{tabular}{lcc}
\hline & Mean & SD \\
\hline Pain Severity & 3.91 & 1.45 \\
Interference & 3.51 & 1.48 \\
Life Control & 3.89 & 1.48 \\
Affective Distress & 2.19 & 1.34 \\
Support & 4.30 & 1.66 \\
Punishing Response & 1.16 & 1.40 \\
Solicitous Response & 3.22 & 1.39 \\
Distracting Response & 2.84 & 1.74 \\
Household Chores & 3.74 & 1.63 \\
Outdoor work & 1.52 & 1.52 \\
Social Activities & 2.37 & 1.13 \\
General Activities & 2.54 & 1.01 \\
\hline
\end{tabular}

TABLE 7. Number of patients according to the MPI-DLV clusters $(n=333)$.

\begin{tabular}{lcc}
\hline & Number & Percentage (\%) \\
\hline Dysfunctional & 90 & 27.0 \\
Interpersonally distressed & 46 & 13.8 \\
Adaptive coper & 33 & 9.9 \\
Average & 82 & 24.6 \\
Anomalous & 82 & 24.6 \\
\hline
\end{tabular}

\section{REFERENCES}

Andersen S, Worm-Pedersen J. The prevalence of persistent pain in a Danish population. Pain 1987; S332.

Andersson HI. The epidemiology of chronic pain in a Swedish rural area. Quality of Life Research 1994; 3: s19-s26.

Aronoff GM, Evans WO, Enders PL A. Review of follow-up studies of multi disciplinary pain units. Pain 1983; 16: 1-11.

Bartelds AIM. Validating of Sentinel Data. Gesundh Wesen 1993; 55: 3-7.

Blyth FM, March LM, Brnabic AJM, Jorm LR, Williamson M, Cousins MJ. Chronic pain in Australia: a prevalence study. Pain 2001; 89: 127-134.

Bonica JJ. The management of pain. 1953 Philidelphia: Lea \& Febiger.

Brattberg G, Thorslund M, Wikman A. The prevalence of pain in a general population. The results of a postal survey in a county of Sweden. Pain 1989; 37: 215-222.

Chapman CR, Gavrin J. Suffering: the contributions of persistent pain. Lancet 1999; 353: 2233-2237.

Claas EC, de Jong JC, Bartelds AIM. Influenza types and patient population. Lancet 1995; 346: 263267.

Clifford JC. Successful management of chronic pain syndrome. Canadian Family Physician 1993; 39: 549-559.

Croft P, Rigby AS, Boswell R, Schollum J, Silman A. The prevalence of chronic widespread pain in the general population. Journal of Rheumatology 1993; 20: 710-713.

Crombie IK, Davies HT, Macrae WA. The epidemiology of chronic pain: time for new directions. Pain 1994; 57: 1-3.

Crook J, Rideout E, Browne G. The prevalence of pain complaints in a general population. Pain 1984; 18: 299-314.

Elliot AM, Smith BH, Penny KI, Smith WC, Chambers WA. The epidemiology of chronic pain in the community. Lancet 1999; 354: 1248-1252.

Gureje O, VonKorff M, Simon GE, Gater R. Persistent pain and well-being. A World Health Organization study in primary care. JAMA 1998; 280: 147-151.

James FR, Large RG, Bushnell JA, Wells JE. Epidemiology of pain in New Zealand. Pain 1991; 44: 279-283.

Kerns RD, Turk DC, Rudy TE. The West-Haven-Yale Multidimensional Pain Inventory WHYMPI. Pain 1985; 23: 345-356.

Kerssens JJ, Groenewegen PP. Referrals to physiotherapy; the relation between the number of referrals the indication for referral and the inclination to refer. Social Science and Medicine 1989; 30: 797-804.

Librach SL. Managing pain in family practice. Canadian Family Physician 1993; 39: 539-544.

Lousberg R, Groenman NH, Schmidt AJM, Arntz A, Winter FAM. Psychometric properties of the Multidimensional Pain Inventory-Dutch Language Version MPI-DLV. Behavioral Research Therapy 1999; 37: 167-182.

Lousberg R, Schmidt AJ, Groenman NH, Vendrig L, Dijkman Caes Cl. Validating the MPI-DLV using experience sampling data. Journal of Behavioral Medicine 1997; 20: 195-206.

Lousberg R. Chronic pain Multiaxial diagnostics and behavioral mechanisms [Thesis]. Maastricht: Universitaire Pers, 1994. 
Kerssens, J.J., Verhaak, P.F.M., Bartelds, A.I.M., Sorbi, M.J., Bensing, J.M. Unexplained severe chronic pain in general practice.

European Journal of Pain: 6, 2002, p. 203-212

Maarse H, Mur Veeman I. Spreeuwenberg C. The reform of hospital care in the Netherlands. Medical Care 1997; 35: Supplement; OS26-39.

Magni G, Carldieron C, Rigatti-Lunchini S, Merskey H. Chronic musculoskeletal pain and depressive symptoms in the general population. An analysis of the 1st National Health and Nutrition Examination Survey data. Pain 1990; 43: 297-307.

Mäkélä M, Heliövaara M. Prevalence of primary fibromyalgia in the Finnish population. British Medical Journal 1991; 303: 216-219.

Mäntyselkä P, Kumpusalo E, Ahonen R, Kumpusalo A, Kauhanen J, Viinamäki H, Halonen P, Takala J. Pain as a reason to visit the doctor: a study in Finnish primary health care. Pain 2001; 89: 175180.

Merskey Ed. Classification of chronic pain. Descriptions of chronic pain syndromes and definition of pain terms. Pain 1986; 39, Supplement 3: s1-s226.

Moons MAW, Peters L, Bartelds AIM, Kerssens JJ. Concerns about AIDS in General Practice. British Medical Journal 1996; 312: 285-286.

Potter R, Jones JM. The evolution of chronic pain among patients with musculoskeletal problems. A pilot study in primary care. British Journal of General Practice 1992; 42: 462-464.

Purves AM. Penny K, Munro C. Defining chronic pain for epidemiological research-assessing a subjective definition. The Pain Clinic 1998; 139-147.

Raspe H, Kohlmann T. Disorders characterised by pain: a methodological review of population surveys. Journal of Epidemiology and Community Health 1994; 48: 531-537.

Rijken PM, Foets M, Peters L, DeBruin AF, Dekker J. Patientenpanel chronisch zieken Kemgegevens 1998. Utrecht: Netherlands institute for primary health care, 1999.

Rudy TE. Multiaxial assessment of pain: Multidimensional pain inventory. Pittsburgh; University of Pittsburgh, 1989.

Seers K. Chronic non-malignant pain. British Journal of General Practice 1992; 42: 452-453.

Sherman RA, Arena JG, Phantom Limb Pain: Mechanisms Incidence and Treatment. Critical Reviews in Physical and Rehabilitation Medicine 1992; 4: 1-26.

Smith BH, Hopton JL, Chambers WA. Chronic pain in primary care. Family Practice 1999; 16: 475482.

Turk DC, Rudy TE. Classification logic and strategies in chronic pain. In: Turk DC, Melzack R, editors. Handbook of pain assessment. New York: Guildford press, 1992.

Verhaak PFM, Kerssens JJ, Dekker J, Sorbi M, Bensing JM. Prevalence of chronic benign pain disorder. A review of the literature. Pain 1998; 77: 231-239.

VonKorff M. Epidemiologic and survey methods: chronic pain assessment. In: Turk DC, Melzack R, editors. Handbook of pain assessment. New York: Guildford press, 1992.

VonKorff M, Dworkin SF, Resche LLe, Kruger A. An epidemiologic comparison of pain complaints. Pain 1988; 32: 173-183.

VonKorff M, Dworkin SF, Resche LLe. Graded chronic pain status: an epidemiological evaluation. Pain 1990; 40: 279-291. 